\title{
SHARPIN regulates cell proliferation of cutaneous basal cell carcinoma via inactivation of the transcriptional factors GLI2 and c-JUN
}

\author{
YAO YANG* ${ }^{*}$ YAN-HUA LIANG* , YAN ZHENG, LING-JIE TANG, SI-TONG ZHOU and JING-NA ZHU \\ Department of Dermatology, Cosmetology and Venereology, Shenzhen Hospital, \\ Southern Medical University, Shenzhen, Guangdong 518101, P.R. China
}

Received October 7, 2018; Accepted January 7, 2020

DOI: $10.3892 / \mathrm{mmr} .2020 .10981$

\begin{abstract}
SHANK-associated RH domain-interacting protein (SHARPIN) is a component of the linear ubiquitin chain assembly complex that can enhance the NF- $\mathrm{KB}$ and JNK signaling pathways, acting as a tumor-associated protein in a variety of cancer types. The present study investigated the role of SHARPIN in cutaneous basal cell carcinoma (BCC). Human BCC $(n=26)$ and normal skin $(n=5)$ tissues, and BCC (TE354.T) and normal skin $(\mathrm{HaCaT})$ cell lines were used to evaluate SHARPIN expression level using immunohistochemistry and western blotting, respectively. A lentivirus carrying SHARPIN-targeting or negative control short hairpin RNA was infected into TE354.T cells, and the infected stable cells were assayed to analyze tumor cell proliferation, cell cycle, apoptosis, migration and invasion by Cell Counting Kit- 8 and 5-ethynyl-2'-deoxyuridine incorporation assays, flow cytometry and Transwell assays. Western blotting was performed to assess the protein expression levels of gene signaling in SHARPIN-silenced BCC cells. SHARPIN protein expression levels were downregulated or absent in BCC cancer nests and precancerous lesions compared with normal skin samples. In addition, SHARPIN expression levels were lower in TE354.T cells compared with HaCaT cells. SHARPIN shRNA enhanced tumor cell proliferation and the $\mathrm{S}$ phase of the cell cycle, whereas BCC cell apoptotic rates, and migratory and invasive abilities were not significantly altered. The expression levels of cyclin D1, cyclin-dependent kinase 4,
\end{abstract}

Correspondence to: Professor Yan-Hua Liang, Department of Dermatology, Cosmetology and Venereology, Shenzhen Hospital, Southern Medical University, 1333 Xinhu Road, Shenzhen, Guangdong 518101, P.R. China

E-mail: liangdoctor@163.com

\section{${ }^{*}$ Contributed equally}

Key words: cutaneous basal cell carcinoma, SHANK-associated RH domain-interacting protein, cell proliferation, c-JUN, GLI family zinc finger 2
phosphorylated-c-JUN and GLI family zinc finger 2 proteins were increased, whereas Patched 1 (PTCH1) and PTCH2 were decreased in the SHARPIN-shRNA-infected BCC cells. Therefore, the present results suggested that SHARPIN may act as a tumor suppressor during BCC development.

\section{Introduction}

Basal cell carcinoma (BCC) is a common type of skin cancer that arises from the innermost layer of the epidermis or from the outer root sheath of the hair follicle (1). According to the American Cancer Society, non-melanoma skin cancer accounts for $>95 \%$ of all skin malignancies, and primarily includes squamous cell carcinoma (SCC) and BCC (2). BCC occurs more frequently in fair-skinned individuals; in the USA alone, there are $\sim 800,000$ new cases each year (3). BCC incidence is the highest in Australia, reaching 726/10,000 individuals each year, whereas in Africa, BCC incidence is the lowest, accounting for $<1 / 10,000$ individuals each year $(4,5)$.

A recent study showed that somatic mutations in normal skin cells were surprisingly high (6). Additionally, $>25 \%$ of sun-exposed skin cells carry cancer-causing mutations in genes that help maintain the normal functions of the epidermis, thus indicating a precancerous state and the promotion of skin cancer development (including BCC, SCC and melanoma) due to sun exposure (7). UV light and genetic susceptibility are important risk factors in BCC development (3), which contribute to a multistep process in BCC development via the accumulation of genetic mutations (3). Previous studies (8-10) have shown that the alteration of Hedgehog $(\mathrm{HH})$ signaling and its synergistic signaling pathway are associated with BCC tumorigenesis, as the $\mathrm{HH}$ signaling pathway plays a critical role in the maintenance of skin stem cells during early embryo and hair follicle development (11). The mammalian HH family of proteins includes three members: Sonic HH, Indian HH and desert HH (12). Under normal circumstances, patched homologue (PTCH), a tumor-suppressor protein, interacts with smoothened protein (SMO) (5). Binding of $\mathrm{HH}$ to $\mathrm{PTCH}$ permits $\mathrm{SMO}$ release, which then activates GLI proteins to promote cell growth and proliferation, and leads to the development of BCC (13-15). Indeed, loss of function of PTCH1 is the most 
frequent mutation in $30-40 \%$ of sporadic BCC cases (16-18), and mutations of genes such as p53, SMO and suppressor of fused protein also occur in BCC (5).

SHANK-associated $\mathrm{RH}$ domain-interacting protein (SHARPIN) is a component of the linear ubiquitin chain assembly complex (LUBAC) and enhances tumor necrosis factor (TNF)-induced NF- $\kappa B$ activity (19). The C-terminal of SHARPIN protein contains a ubiquitin-like domain and a Nuclear protein localization protein 4 zinc finger (NZF), with a significant sequence homology to the longer isoform of heme-oxidized iron-regulatory protein 2 ubiquitin ligase-1 (HOIL-1L), while the $\mathrm{N}$-terminal contains a coiled-coil region that can mediate the polymerization (20). SHARPIN, HOIL-1 and HOIL-1L interacting protein (HOIP) together comprise the LUBAC, catalyzing the formation of linear ubiquitin chains, and regulating the activation of the $\mathrm{NF}-\kappa \mathrm{B}$ and JNK signaling pathways (21). The ubiquitin-like domain of SHARPIN specifically binds to the ubiquitin-associated domain of HOIP to associate with and activate HOIP; furthermore, SHARPIN and HOIL-1L can separately or synergistically facilitate the E2 loading of HOIP for its activation (22). Fujita et al (23) demonstrated that inhibition of LUBAC-tethering motifs-mediated HOIL-1L/SHARPIN dimerization profoundly attenuates the function of LUBAC. Shimizu et al (24) showed that the binding of K63-linked ubiquitin chains to the NZF domain of SHARPIN, but not HOIL-1L, appears to be involved in the recruitment of LUBAC. Thus, selective recognition of ubiquitin chains by NZFs in LUBAC underlies the regulation of LUBAC function (24). Loss of function of SHARPIN in mice leads to the development of an idiopathic hypereosinophilic syndrome with eosinophilic dermatitis (25). However, the geographical heterogeneity of SHARPIN in various areas of the skin has not been investigated. Previous studies showed that SHARPIN is a cancer-associated gene. For example, Jung et al (26) demonstrated that SHARPIN was upregulated in clear cell adenoma, hepatocellular carcinoma and papillary serous adenocarcinoma. Additionally, several studies showed that SHARPIN participated in the development of non-small cell lung cancer, melanoma, mycosis fungoides, breast cancer, prostate cancer and osteosarcoma (19,27-31). Previous studies showed that the activation of the $\mathrm{NF}-\kappa \mathrm{B}$ pathway induced Sonic $\mathrm{HH}$ expression (32-34), and that UV light could also induce the activation of the $\mathrm{NF}-\kappa \mathrm{B}$ pathway during $\mathrm{BCC}$ development (35-37).

Based on the BCC pathogenesis and the biological functions of SHAPRIN in tumorigenesis, the present study investigated the potential role of SHARPIN in skin BCC and the underlying molecular mechanisms.

\section{Materials and methods}

Tissue samples. Tissues were fixed with $10 \%$ formalin for $\sim 4 \mathrm{~h}$ at room temperature. Then, formalin-fixed paraffin-embedded blocks of 26 BCC samples, five normal skin samples and one breast cancer sample were collected from The Affiliated Hospitals of Southern Medical University from July 2016 to December 2018. BCC was diagnosed by experienced dermatologists and confirmed via histopathological analysis. Breast cancer was diagnosed by a pathologist. This study was approved by The Ethics Committee of Shenzhen Hospital,
Southern Medical University, and all participants signed written informed consent forms.

Immunohistochemistry. Paraffin-embedded sections (thickness, $4 \mu \mathrm{m}$ ) were prepared and deparaffinized in xylene, and then rehydrated in a series of diluted ethanol solutions (100-70\%). The endogenous peroxidase activity was blocked for $30 \mathrm{~min}$ by incubation in $1 \%$ methanolic hydrogen peroxide solution at room temperature. This was followed by incubation with 20\% goat serum (cat. no. C0265; Beyotime Institute of Biotechnology) to minimize non-specific binding of the secondaryantibody (ready-to-useperoxidaseanti-Mouse/Rabbit IgG; cat. no. PV-9000; OriGene Technologies, Inc.) and subsequently with rabbit anti-SHARPIN (1:100; cat. no. sc-98127; Santa Cruz Biotechnology, Inc.), anti-cyclin D1 (1:200; cat. no. WL01435a; Wanleibio Co., Ltd.), anti-cyclin-dependent kinase 4 (CDK4; 1:5,000; cat. no. 12790; Cell Signaling Technology, Inc.), antic-JUN (1:1,000; cat. no. 9165; Cell Signaling Technology, Inc.) and anti-GLI family zinc finger 2 (GLI2; 1:200; cat. no. sc-28674; Santa Cruz Biotechnology, Inc.) at $4^{\circ} \mathrm{C}$ overnight. On the next day, the sections were subjected to a two-step plusPoly-horseradish peroxidase anti-Mouse/Rabbit IgG Detection System (cat. no. PV-9000; OriGene Technologies, Inc.) at room for $1 \mathrm{~h}$ temperature and 3,3-diaminobenzidine Detection kit (Enhanced Polymer; cat. no. PV-9000-D; OriGene Technologies, Inc.). The immunostaining results were analyzed using the cross-product $\mathrm{H}$ score, where the staining intensity was graded on a four-point scale: i) 0 , no staining; ii) $1+$, weak; iii) $2+$, moderate; and iv) $3+$, strong staining (38). The $\mathrm{H}$ score=tumor cell staining percentage $\mathrm{x}$ staining intensity for SHARPIN expression, according to a previous study (39). In addition, the expression levels of cyclin D1, CDK4, c-JUN and GLI2 were searched in the Human Protein Atlas website (HPA; https://www.proteinatlas.org/; Version 16.1).

Cell lines and culture. The human BCC TE354.T cell line $(40,41)$ was purchased from the American Tissue Culture Collection (cat. no. CRL-7762 ${ }^{\mathrm{TM}}$ ). HaCaT cells, an immortalized non-tumorigenic human keratinocyte cell line (42) was obtained from Nanjing KeyGen Biotech. Co., Ltd. (cat. no. KG300). HaCaT cells have been authenticated using STR profiling. Both TE354.T and HaCaT cell lines were cultured in DMEM (cat. no. C11995500BT; Gibco; Thermo Fisher Scientific, Inc.) supplemented with $10 \%$ FBS (cat. no. 10270; Gibco; Thermo Fisher Scientific, Inc.) and 1\% penicillin-streptomycin (cat. no. SV30010; GE Healthcare Life Sciences) in a humidified incubator with $5 \% \mathrm{CO}_{2}$ at $37^{\circ} \mathrm{C}$.

Western blotting. Cells were lysed in RIPA buffer (cat. no. 20-188; EMD Millipore) containing a protease inhibitor (cat. no. CW2200S; Beijing CoWin Biotech Co., Ltd.). The protein concentration was measured using a bicinchoninic acid assay kit (cat. no. E112, Vazyme Biotech Co., Ltd.). Then, $10 \mu \mathrm{l}$ protein lysates were subjected to $12 \%$ SDS-PAGE and transferred onto PVDF membranes (EMD Millipore). For western blotting, the membranes were blocked in 5\% non-fat milk for $1 \mathrm{~h}$ at room temperature and then incubated with antibodies against SHARPIN (1:2,000; cat. no. ab197853; Abcam), cyclin D1 (1:800; cat. no. WL01435a; Wanleibio 
Co., Ltd.), CDK4 (1:1,000; cat. no. 12790; Cell Signaling Technology, Inc.), c-JUN (1:2,000; cat. no. 9165; Cell Signaling Technology, Inc.), phosphorylated (p)-c-JUN (1:1,000; cat. no. 2361; Cell Signaling Technology, Inc.), GLI1 (1:1,000; cat. no. 8358; Cell Signaling Technology, Inc.), GLI2 (1:200; cat. no. sc-28674; Santa Cruz Biotechnology, Inc.), PTCH1 (1:1,000; cat. no. 2468; Cell Signaling Technology, Inc.), PTCH2 (1:1,000; cat. no. 2470; Cell Signaling Technology, Inc.) and $\beta$-actin (1:2,000; cat. no. AC001-R; Beijing Dingguo Changsheng Biotechnology Co., Ltd.) at $4^{\circ} \mathrm{C}$ overnight. On the next day, the membranes were incubated for $1 \mathrm{~h}$ with horseradish peroxidase-conjugated immunoglobulin (1:2,500; cat. no. bs-0295G-HRP; Bioss Antibodies) in room temperature and then detected using a High-Sensitive ECL Chemiluminescence Detection kit (cat. no. E411; Vazyme Biotech Co., Ltd.). The membranes were exposed using an imaging system (Canon 5200; Canon Inc.). The protein expression level was quantified using Image Pro Plus (43).

Generation of a SHARPIN-deficient stable cell line. Lentiviral vectors carrying SHARPIN short hairpin RNA [shRNA; sh-SHARPIN; pLV(shRNA)-EGFP:T2A:Puro-U6 >hSHARPIN(shRNA2); Vector ID: VB150923-10005] and the negative control [sh-Ctrl; pLV(shRNA)-EGFP:T2A:Puro -U6>Scramble shRNA; Vector ID: VB151023-10034] were designed and synthesized by Cyagen Biosciences, Inc. The SHARPIN shRNA sequence was 5'-CCCTGGAGTCAGTTT CCTACA-3', and the sh-Ctrl sequence was 5'-CCTAAGGTT AAGTCGCCCTCG-3'. These lentivirus vectors, including an enhanced green fluorescent protein and an antibiotic resistance gene against puromycin, were transfected into 293T cells (cat. no. 3111C0001CCC000091; National Infrastructure of Cell Line Resource) for lentivirus production. 293T cells were cultured in DMEM supplemented with $10 \%$ FBS and $1 \%$ penicillin-streptomycin in a humidified incubator with $5 \% \mathrm{CO}_{2}$ at $37^{\circ} \mathrm{C}$. The lentiviruses (Transducing units, $1 \times 10^{8} \mathrm{TU} / \mathrm{ml}$ ) were transfected into TE354.T cells (3-5x10\% $/$ well in 6-well) with $5 \mu \mathrm{g} / \mathrm{ml}$ polybrene according to the manufacturer's protocol; polybrene is a transfection reagent with a positive charge, so it can bind to the anion on the cell surface to facilitate and significantly increase the transfection efficiency. After $72 \mathrm{~h}$ of cell transfection, green fluorescence was observed under a fluorescence microscope at x200 magnification (Olympus IX71; Olympus Corporation). Then, the cells were cultured in DMEM supplemented with $10 \%$ FBS, $1 \%$ penicillin-streptomycin and $0.5 \mu \mathrm{g} / \mathrm{ml}$ puromycin to obtain stable cell lines.

Reverse transcription-quantitative PCR (RT-qPCR). Total cellular RNA was isolated from the SHARPIN-shRNA lentivirus infected cells using TRIzol ${ }^{\circledR}$ reagent (cat. no. 15596026; Invitrogen; Thermo Fisher Scientific, Inc.). Then, $1 \mu \mathrm{g}$ RNA was added with $4 \mu 1$ 5X HiScript II qRT SuperMix II (HiScript ${ }^{\circledR}$ II Reverse Transcriptase; cat. no. R223; Vazyme Biotech Co., Ltd.) to form a $20 \mu \mathrm{l}$ mixture, which was placed in an ABI3130 automated sequencer (Applied Biosystems; Thermo Fisher Scientific, Inc.). The following RT conditions were used: Reacted at $25^{\circ} \mathrm{C}$ for $10 \mathrm{~min}, 50^{\circ} \mathrm{C}$ for $30 \mathrm{~min}$ and $85^{\circ} \mathrm{C}$ for $5 \mathrm{~min}$, for RT into cDNA using HiScript II Reverse Transcriptase (cat. no. R223; Vazyme Biotech Co., Ltd.). qPCR was then performed using an ABI 7500 RT PCR system
(Applied Biosystems; Thermo Fisher Scientific, Inc.) with ChamQ SYBR qPCR Master mix (cat. no. Q331; Vazyme Biotech Co., Ltd.). The qPCR conditions were as follows: Initial denaturation at $95^{\circ} \mathrm{C}$ for $5 \mathrm{~min}$; followed by 40 cycles of $95^{\circ} \mathrm{C}$ for $30,72^{\circ} \mathrm{C}$ for $30 \mathrm{sec}$ and $58^{\circ} \mathrm{C}$ for $30 \mathrm{sec}$; and a final extension at $72^{\circ} \mathrm{C}$ for $10 \mathrm{~min}$. The level of $\beta$-actin mRNA was used as the endogenous control. Primer sequences used were as follows: SHARPIN forward, 5'-TGTTCTCAGAGCTCG GTTT-3' and reverse, 5'-AAGTTCCCCGTCCATCTT-3'; and $\beta$-actin forward, 5'-GGATGCAGAAGGAGATCACTG-3' and reverse, 5'-CGATCCACACGGAGTACTTG-3'. All reactions were performed in triplicate and repeated $\geq 1$ time. The relative level of SHARPIN mRNA was calculated using the $2^{-\Delta \Delta C q}$ method (44).

Cell counting Kit-8 (CCK-8) and 5-ethynyl-2'-deoxyuridine (EdU)-incorporation assays. A CCK-8 (cat. no. CK04; Dojindo Molecular Technologies, Inc.) and EdU labeling kit, containing EdU labeling media, Apollo reaction buffer, Apollo catalyst solution, Apollo fluorescent dye solution and Apollo buffer additive (cat. no. C10310-3; Guangzhou RiboBio Co., Ltd.), were used to investigate cell viability and proliferation in SHARPIN knockdown BCC cells. Stable TE354.T cells were seeded into 96 -well plates at a density of $5 \times 10^{3} /$ well in 6-wells in each group for a final volume of $100 \mu \mathrm{l}$ and cultured for 3 days. At the end of 24, 48 and 72 h, $10 \mu \mathrm{l}$ of the CCK-8 solution was added into each well and the cells were incubated for $45 \mathrm{~min}$ in a humidified incubator with $5 \% \mathrm{CO}_{2}$ at $37^{\circ} \mathrm{C}$, according to the manufacturer's instructions. The optical absorbance rate of the cell solution was measured using a Multimode Plate reader (PerkinElmer, Inc.) at $450 \mathrm{~nm}$.

Stable sh-SHARPIN TE354.T cells and negative controls were grown at a density of $8 \times 10^{3} /$ well in 96 -well plates for $48 \mathrm{~h}$. Then, $50 \mu \mathrm{M}$ EdU labeling media was added into each well of the 96-well plates and incubated in a humidified incubator with $5 \% \mathrm{CO}_{2}$ at $37^{\circ} \mathrm{C}$ for $4 \mathrm{~h}$. The cells were fixed with $4 \%$ paraformaldehyde for $30 \mathrm{~min}$ at room temperature and treated with $0.05 \%$ Triton X-100 solution for $10 \mathrm{~min}$ at room temperature. Next, the cells were immunostained for $30 \mathrm{~min}$ in the dark at room temperature with Apollo working solution containing $25 \mu \mathrm{l}$ of Apollo reaction buffer, $5 \mu \mathrm{l}$ of Apollo catalyst solution, $1.5 \mu \mathrm{l}$ of Apollo fluorescent dye solution, $5 \mathrm{mg}$ of Apollo buffer additive and $469 \mu \mathrm{l}$ of deionized water. Then, the cell nuclei were stained with DAPI solution at room temperature in the dark for $15 \mathrm{~min}$ according to the manufacturer's instructions (cat. no. DA0001; Beijing Leagene Biotechnology Co., Ltd.). The stained cells were observed under a fluorescence microscope at x200 magnification, and five fields were randomly photographed for each group. The EdU-positive cells and DAPI cells in each field were counted. The proliferation rate was calculated using the following formula: Proliferation rate=the green fluorescence-positive cells (proliferating cells)/the blue fluorescence cells (total cells) $\mathrm{x} 100 \%$.

Cell cycle analysis using flow cytometric assays. TE354.T cells were plated into 6 -well plates at a density of $4 \times 10^{5}$ cells/well and cultured for $48 \mathrm{~h}$. Then, the cells were washed twice with ice-cold PBS, fixed with $75 \%$ ethanol at $-20^{\circ} \mathrm{C}$ overnight and stained with $400 \mu \mathrm{l}$ propidium iodide (cat. no. KGA512L; 
Nanjing KeyGen Biotech Co., Ltd.) at $4^{\circ} \mathrm{C}$ in the dark for $30 \mathrm{~min}$. Cell distribution was measured using a flow cytometer (FACSCalibur; BD Biosciences; FlowJo, Version 10) at in $488 \mathrm{~nm}$.

Annexin $V$ assays. Apoptosis was detected using a Annexin V-allophycocyanin (APC) kit (cat. no. 88-8007) and 7-aminoactinomycin D (7-ADD) solution (cat. no. 00-6993; both eBioscience; Thermo Fisher Scientific, Inc.). An Annexin V-APC/7-ADD apoptosis assay was used to assess tumor cell apoptosis after sh-SHARPIN shRNA and sh-Ctrl transfection into BCC cells, according to the manufacturer's instructions. TE354.T cells $\left(2 \times 10^{5}\right)$ were plated into 6-well plates and cultured for $48 \mathrm{~h}$. Cells were washed with PBS and then in $1 \mathrm{X}$ binding buffer (cat. no. 00-0055; eBioscience; Thermo Fisher Scientific, Inc.), and resuspended in $1 \mathrm{X}$ binding buffer at $3 \times 10^{5} / \mathrm{ml}$. Then, $5 \mu \mathrm{l}$ of fluorochrome-conjugated Annexin $\mathrm{V}$ was added to $100 \mu \mathrm{l}$ of the cell suspension and incubated for 10-15 min at the room temperature. Cells were washed again in $1 \mathrm{X}$ binding buffer and resuspended in $200 \mu \mathrm{l}$ of $1 \mathrm{X}$ binding buffer. Then, $5 \mu \mathrm{l}$ of 7-AAD viability staining solution was added into the mixture and analyzed within $4 \mathrm{~h}$ at $2-8^{\circ} \mathrm{C}$ in the dark. The cells were analyzed with a BD FACSCalibur flow cytometer.

Transwell assay. Transwell units with $8-\mu \mathrm{m}$ pore size membranes were obtained from Falcon (cat. no. 353097; Corning Inc.). TE354.T cells were harvested and suspended in serum-free DMEM medium and seeded $\left(3 \times 10^{4}\right.$ cells) in Transwell upper chambers, which were precoated with or without Matrigel (cat. no. 354234; Corning Inc.). DMEM with $10 \%$ FBS was added into the lower chambers. The cells were cultured for $16 \mathrm{~h}$ in a humidified incubator with $5 \% \mathrm{CO}_{2}$ at $37^{\circ} \mathrm{C}$, and the cells in the upper chamber were removed using a cotton swab, while the cells that migrated or invaded into the lower chambers were fixed with $4 \%$ paraformaldehyde for $30 \mathrm{~min}$ at room temperature and stained with $0.5 \%$ crystal violet solution at room temperature for $20 \mathrm{~min}$. The number of migrated or invaded cells were counted in ten randomly selected fields (BX51; Olympus Corporation; magnification, $\mathrm{x} 200$ ) and the rates were calculated by comparing with the control cells.

Statistical analysis. The statistical analysis was performed using SPSS 13.0 software (SPSS, Inc.). SHARPIN expression levels in BCC subtypes and normal skin were analyzed using Kruskal-Wallis tests followed by Dunn's post hoc test. Age and sex data in BCC were analyzed using Mann-Whitney U tests. The data on the cell biological functions assays were analyzed using an independent sample t-tests. $\mathrm{P}<0.05$ was considered to indicate a statistically significant differences.

\section{Results}

Reduced or absent expression of SHARPIN in BCC tissues and cell lines. Subcategories of BCC tissues in the donor demographic profile, risk factors, subtypes and tissue-biopsy locations are summarized in Table SI. The present study assessed the expression level of SHARPIN in 26 BCC tissues compared with five healthy skin tissues, and also in two cell
Table I. Subcategory-analysis in BCC.

\begin{tabular}{lcc}
\hline Characteristic & H Score & P-value \\
\hline Sex & & $>0.05$ \\
Female & $92.69 \pm 68.27$ & \\
Male & $53.85 \pm 61.45$ & $>0.05$ \\
Age & & \\
$<60$ & $55.00 \pm 63.17$ & \\
$\geq 60$ & $85.36 \pm 71.32$ & $>0.05$ \\
BCC subtype & & \\
Nodular type & $98.00 \pm 75.69$ & \\
Superficial type & $53.13 \pm 37.12$ & \\
Adenoidal type & $62.50 \pm 75.17$ & \\
\hline
\end{tabular}

Data are presented as the mean $\pm \mathrm{SD}$. BCC, cutaneous basal cell carcinoma.

lines. The present results suggested that SHARPIN expression was not significantly associated with age, sex or subtype in BCC tissue samples (Table I). However, SHARPIN protein expression level was downregulated or absent in precancerous lesions and cancer nests of BCCs compared with the expression levels in healthy skin tissues (Fig. 1A-D). In addition, SHARPIN protein expression level was significantly decreased in TE354.T cells compared with HaCaT cells (Fig. 1E and F). To assess these results, the SHARPIN expression level in breast cancer was used as a control for the assay (Fig. S1). To investigate the expression levels of cyclin D1, CDK4, c-JUN and GLI2 in BCC tissues, the HPA website was searched and the following results were showed: i) Cyclin D1 was low in three cases; ii) CDK4, six cases with one low, one high, three medium and one unknown; iii) JUN, six cases with one medium and five high; and iv) GLI2, five cases all high, compared with healthy skin tissues. The present results suggested that cyclin D1 was highly expressed in three BCC samples and moderately expressed in two BCC samples compared with healthy skin. CDK4 expression in BCC tissues (one low, three medium and one high) exhibited $80 \%$ high expression compared with healthy skin tissues. In addition, c-JUN expression was one high and four medium cases compared with healthy skin tissues, and GLI2 expression in BCC tissues was two high and three medium cases compared with healthy skin tissues (Fig. S2).

Activation of tumor cell proliferation after SHARPIN knockdown. SHARPIN expression was decreased in BCC tissue and TE354.T cells compared with normal tissue and cells; thus, the present study generated a stable SHARPIN knockdown cell subline and performed cell viability and proliferation assays. The present results suggested that the mRNA and protein expression levels of SHARPIN in sh-SHARPIN group were significantly decreased compared with the negative control (Fig. 2A and B). The stable knockdown of SHARPIN significantly increased BCC cell proliferation and viability (Fig. 2C-E), while the cell cycle distribution assay results suggested that more sh-SHARPIN-infected cells were in 

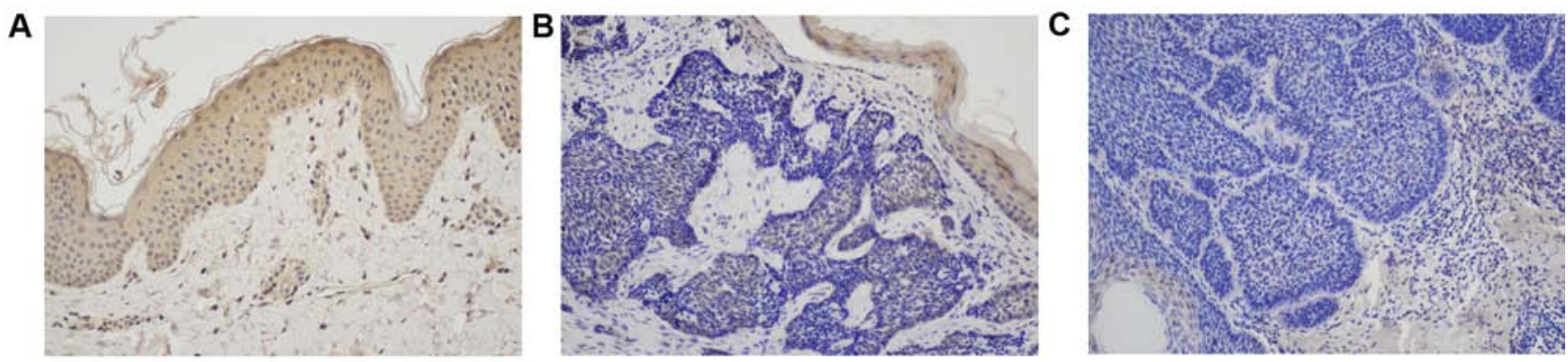

D

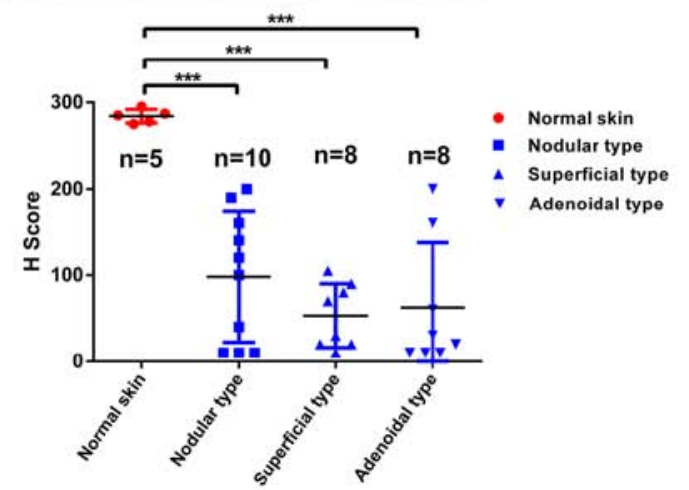

E

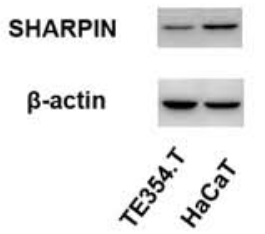

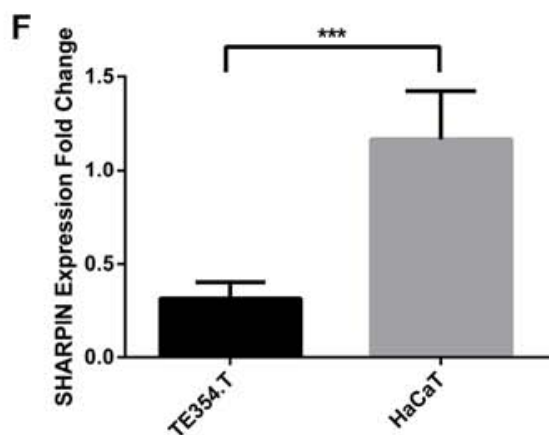

Figure 1. Decreased SHARPIN in BCC tissues and TE354.T cells. SHARPIN was analyzed using immunohistochemistry in 26 BCC tissues and 5 healthy skin samples. (A) Normal skin. Magnification, x200. (B) BCC cancer nest. Magnification, x200. (C) Another BCC cancer nest. Magnification, x200. (D) Quantified immunostaining data using $\mathrm{H}$ score in different BCC subtypes and healthy skin. (E) Western blotting results for the protein expression of SHARPIN in TE354.T and HaCaT cell lines. (F) Quantification of western blot analysis. ${ }^{* * *} \mathrm{P}<0.001$. SHARPIN, SHANK-associated RH domain-interacting protein; BCC, cutaneous basal cell carcinoma.

the $\mathrm{S}$ phase compared with negative control cells (Fig. 2F). However, there were no significant differences in tumor cell apoptosis, migration or invasion between the SHARPIN knockdown and negative control cells (Fig. S3).

At the molecular level, the expression levels of cyclin D1 and CDK4 in sh-SHARPIN group were increased compared with the negative control group (Fig. 3A and B).

JNK/GLI2 signaling pathwayisactivatedinSHARPIN-silenced TE354.T cells. The present study investigated the underlying molecular mechanism of the effects of SHARPIN in BCC cells by analyzing the protein expression levels of c-JUN, p-c-JUN, GLI1, GLI2, PTCH1 and PTCH2. It was shown that, compared with the negative control group, the protein expression levels of p-c-JUN and GLI2 were significantly increased, while PTCH1 and PTCH2 were decreased in SHARPIN knockdown cells. In addition, the protein expression levels of c-JUN were decreased, while GLI1 expression was not significantly different between the two groups (Fig. 3C-H).

\section{Discussion}

The present study identified that SHARPIN expression level was decreased in BCC tissues and TE354.T cell lines. Using the stable SHARPIN knockdown cell subline, it was identified that SHARPIN shRNA enhanced TE354.T tumor cell proliferation and the number of cells in the $S$ phase of the cell cycle. At the molecular level, SHARPIN knockdown promoted the protein expression levels of cyclin D1, CDK4, p-c-JUN and GLI2. Collectively, the present results suggested that SHARPIN may act as a tumor suppressor gene during $\mathrm{BCC}$ tumorigenesis.
Previous studies have shown that SHARPIN is involved in the development of various human cancer types. For example, overexpression of SHARPIN contributed to prostate cancer development by activating survivin and livin, which are downstream targets of the NF- $\kappa \mathrm{B}$ signaling pathway (45). Additionally, SHARPIN can promote the activation of the $\mathrm{NF}-\kappa \mathrm{B} / \mathrm{ERK} / \mathrm{Akt}$ signaling pathway and induce prostate cancer tumorigenesis by regulating the expression of the transforming apoptosis-associated protein (28). A significant elevation of SHARPIN mRNA expression has been reported in breast cancer (46). SHARPIN expression is associated with poor prognosis in patients with breast cancer $(19,27)$. These studies reporting SHARPIN overexpression have provided evidence of its function as an oncogene in the specific cancer types described above. The present results suggested that SHARPIN was downregulated in BCC tissues. BCC is different from other human cancer types, as it proliferates slow, locally and rarely metastasizes to other organs; thus, BCC has a more favorable prognosis $(1,47)$. However, further study is required to investigate the tissue-specific role of SHARPIN in tumorigenesis.

The hallmarks of cancer cells encompass six biological capabilities, including limitless replicative potential, evading apoptosis, self-sufficiency in growth signals, insensitivity to antigrowth signals, sustained angiogenesis, and tissue invasion and metastasis $(48,49)$. Upon stimulation by internal and external factors, normal cells show a series of abnormal activities, such as genetic mutations, altered cell cycle, unlimited cell proliferation and reduced cell apoptosis; these cells eventually transform into tumor cells (50). The present study generated a stable SHARPIN-silencing TE354.T cell line 
A

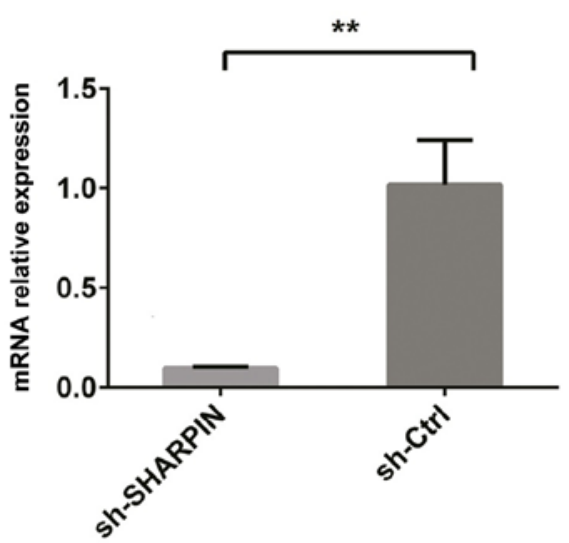

B

\section{SHARPIN}

$\beta$-actin

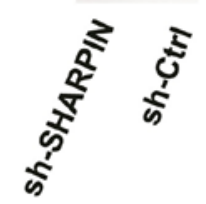

C

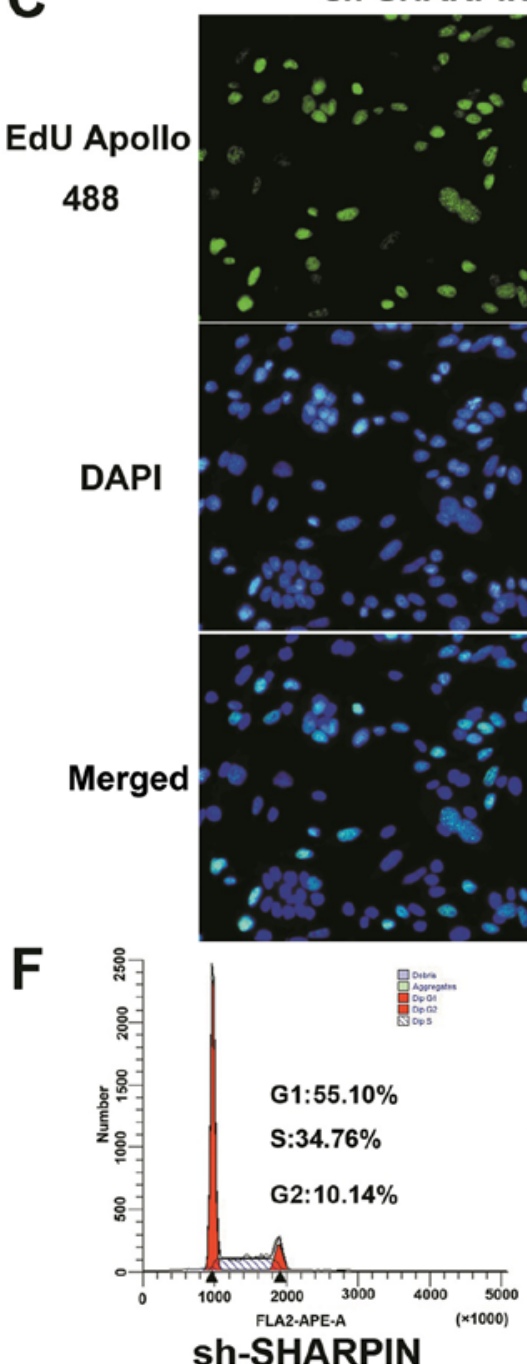

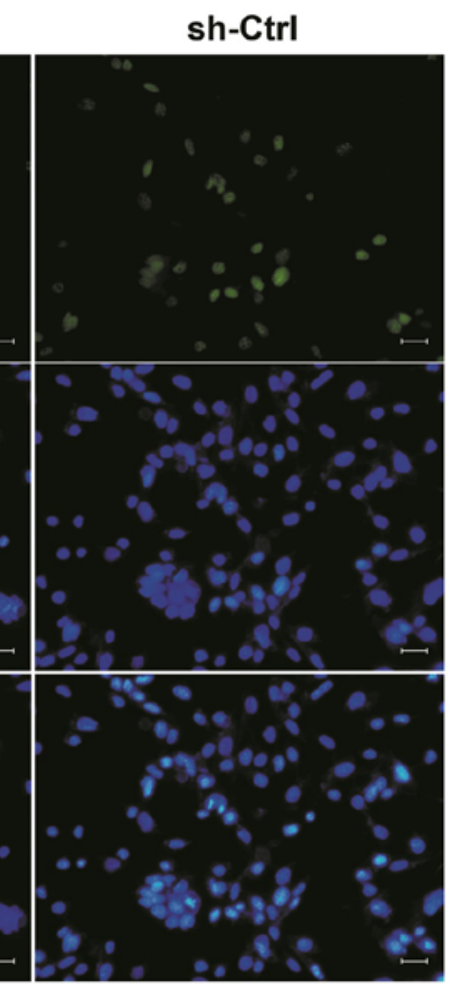

D

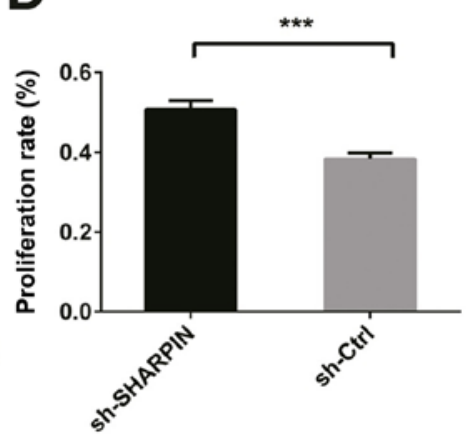

E

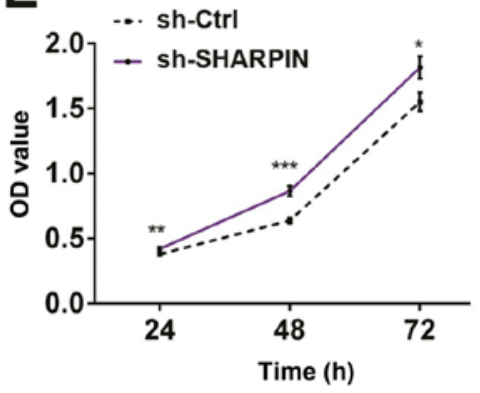

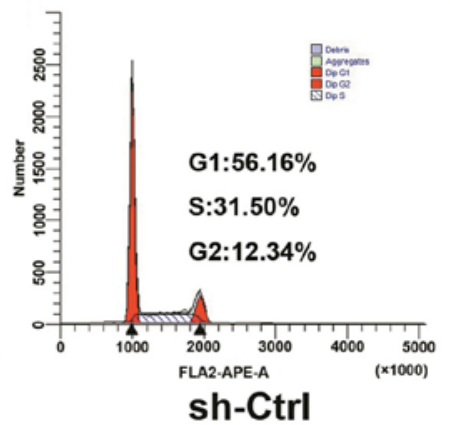

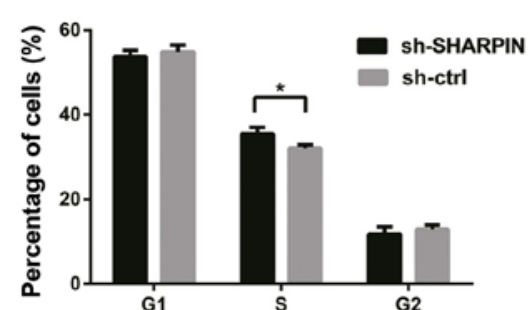

Figure 2. Effect of SHARPIN on the regulation of BCC cell proliferation. TE354.T cells were cultured, infected with SHARPIN shRNA and subjected to various assays. Stable TE354.T cells were grown, and the expression levels of SHARPIN were examined via (A) reverse transcription-quantitative PCR and (B) western blotting. (C) EdU incorporation assay in TE354.T-sh-SHARPIN transfected cells and negative controls. Magnification, x200. (D) Quantified data from EdU assay. (E) Cell viability was assessed using Cell Counting Kit-8 assay. (F) Flow cytometric cell cycle assay. ${ }^{*} \mathrm{P}<0.05,{ }^{* * *} \mathrm{P}<0.01,{ }^{, * * *} \mathrm{P}<0.001$. SHARPIN, SHANK-associated RH domain-interacting protein; BCC, cutaneous basal cell carcinoma; sh(RNA), short hairpin RNA; EdU, 5-ethynyl-2'-deoxyuridine; sh-Ctrl, shRNA control; OD, optical density.

and assessed tumor cell proliferation, apoptosis, invasion and migration. The present results suggested that the proliferative ability of silenced-SHARPIN BCC cells was significantly increased compared with corresponding control cells. Cell proliferation refers to the ordered, tightly regulated process involving cell number increases, nutrients accumulation and cell division (51). Purba et al (52) demonstrated that an increase in the distribution of cells in the $\mathrm{S}$ phase of the cell cycle could be sensitively and accurately assessed in tumor cells using BrdU or EdU incorporation assays. The present 
A
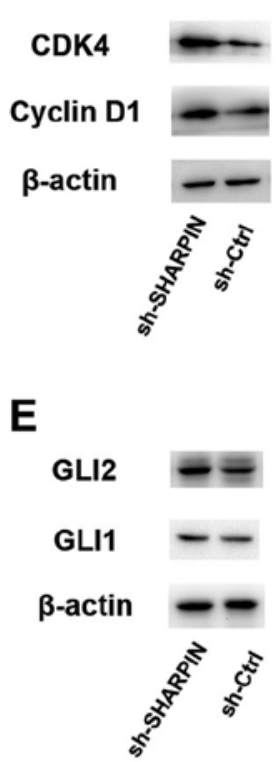

B
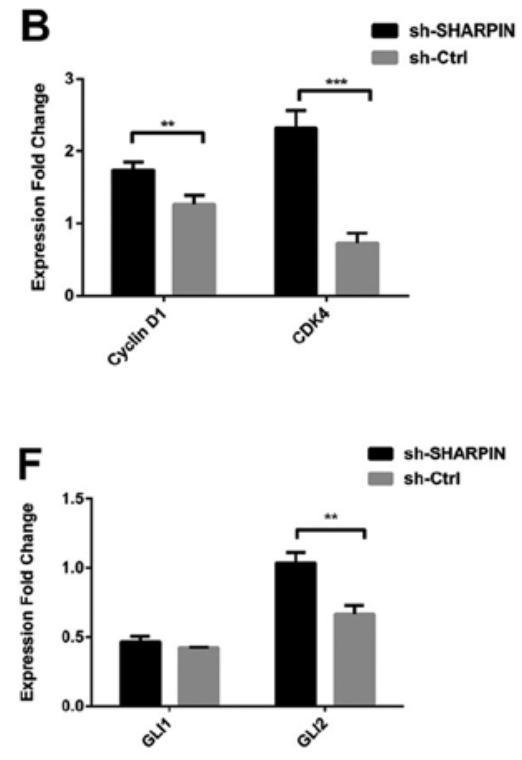

C
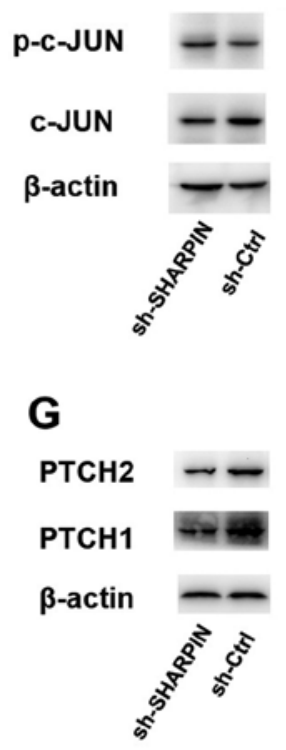

D
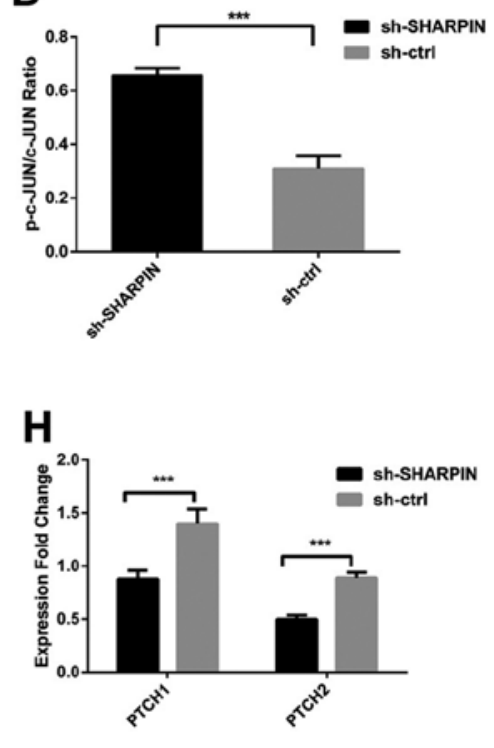

Figure 3. Effects of SHARPIN on the expression levels of relevant proteins. Stable TE354.T cells were grown and analyzed via western blot assays. (A) Western blotting and (B) quantification of cyclin D1 and CDK4 expression. (C) Western blotting and (D) quantification of c-JUN and p-c-JUN expression. (E) Western blotting and (F) quantification of GLI1 and GLI2 expression. (G) Western blotting and (H) quantification of PTCH1 and PTCH2 expression. ** P<0.01, ${ }^{* * *} \mathrm{P}<0.001$. SHARPIN, SHANK-associated RH domain-interacting protein; p-, phosphorylated; GLI, Glioma-associated oncogene homolog; PTCH, patched homologue; shRNA, short hairpin RNA; sh-Ctrl, shRNA-control.

study identified that EdU-positive cells were more numerous in sh-SHARPIN-transfected BCC cells compared with negative control transfected cells. Therefore, the loss of function of SHARPIN could induce cell proliferation via an increase in $\mathrm{S}$ phase cell cycle stage.

The cell cycle is a complicated dynamic process that generates daughter cells via DNA replication and cell division (53). The cell cycle can be divided into the resting phase (G0), the beginning stage of DNA synthesis (G1), DNA replication stage (S) and the late stage of DNA synthesis (G2) (53). The transition from the G1 phase to $S$ phase is a critical step in determining the rate of cell proliferation, and is modulated by the phosphorylation of retinoblastoma ( $\mathrm{Rb})(54)$. CDKs are serine/threonine kinases that are regulated by interactions with cyclins and CDK inhibitors, and are the key regulators of the G1-to-S checkpoint (55). After CDK4 binds with its catalytic partner cyclin $\mathrm{D}$ to form an active complex, $\mathrm{Rb}$ is consecutively phosphorylated, thus relieving its inhibition on E2F to allow target genes to promote the G1-to-S phase entry (56). The present results indicated that the expression levels of cyclin D1 and CDK4 were increased in SHARPIN knockdown BCC cells, which suggested that silencing SHARPIN could promote cell proliferation via the overexpression of cyclin D1 and CDK4.

The HH signaling pathway plays a critical role in the development of BCC (57). Decreased expression levels of PTCH1 and PTCH2, which are tumor suppressor genes, can promote the development of BCC (58). Moreover, the activation of GLI has been identified to be responsive to certain pathways, such as the AKT/PI3K, RAS/RAF/mitogen-activated protein kinase (MAPK) kinase (MEK)/ERK and epidermal growth factor (EGF) signaling pathways (59-61). Schnidar et al (62) revealed that $\mathrm{EGF}$ receptor (EGFR)/MEK/ERK signaling in combination with the GLI activator results in GLI1- and GLI2-induced activation of JUN/activator protein 1 (AP-1), which is essential for oncogenic transformation in human keratinocytes cells. Moreover, the inhibition of EGFR and $\mathrm{HH} / \mathrm{GLI}$ was able to effectively slow the growth of a mouse BCC cell line (62). Laner-Plamberger et al (63) showed significantly increased expression levels of c-JUN in human BCC tissue samples. In addition, GLI1 and GLI2 can directly upregulate the expression levels of AP-1 family members c-JUN and GLI2 more effectively than the expression of GLI1 (63), which is consistent with the present results.

The JUN family includes c-JUN, JUN B and JUN D as downstream proteins of the JNK signaling pathway (64). A number of stimulators, such as growth factors, cytokines, UV light and stress, can activate JNK via the MAPK cascade to increase the transcription of AP-1 by phosphorylating c-JUN at the serine 63 and serine 73 sites (65). The JNK pathway regulates cell proliferation, differentiation and apoptosis, as well as tumor cell invasion and metastasis $(66,67)$. c-JUN is essential in embryonic development (68). Zenz et al (69) showed that cell proliferation was reduced in $\mathrm{JUN}^{-/-}$keratinocytes, and that c-JUN-promoted cell proliferation occurred via the activation of cyclin D1 and other cell cycle-related proteins in keratinocytes. Moreover, the regulation of cyclin D1 expression was shown to be caused by binding to the cyclin D1 promoter $(64,70)$. In addition, GLI2 has been confirmed to accelerate the transformation of the G1 phase of the cell cycle to the $\mathrm{S}$ phase via the activation of E2F1, cyclin D1, CDC45L and other cell cycle-related proteins (71). In the present study, the knockdown of SHARPIN induced cyclin D1 and c-JUN activation, which is inconsistent with the previous results showing that SHARPIN induced $N F-\kappa B$ and thus 
promoted AP-1 activity in various cells (72). LUBAC can activate the MAPK cascade signaling pathway, which involves JNK, p38 and ERK1/2, to increase the expression levels of AP-1 and c-JUN (73). TNF- $\alpha$-induced JNK/ERK activation is enhanced in chronic proliferative dermatitis mice (cpdm) embryonic fibroblasts (MEFs) compared with wild-type MEFs (73). Knockdown of cpdm partially results in an increase in JUN phosphorylation to cause signal dependence or determine the specificity of the cell type $(21,73)$.

However, the expression levels of cyclin D1, CDK4, c-JUN and GLI2 in present study were not consistent with previous studies or those from The Human Protein Atlas. Sivrikoz and Kandiloğlu (74), Liang et al (75) and Huang et al (76) showed that the expression level of cyclin D1 was higher in BCC tissues compared with healthy skin. Laner-Plamberger et al (63) reported a higher expression level of JUN in BCC tissues. Data on the expression of GLI2 in a previous study (77) and the analysis in present study were consistent. It was demonstrated that cyclin D1, c-JUN and GLI2 were highly expressed in BCC samples compared with healthy skin, which was mostly consistent with previous studies (74-77). The expression of CDK4 in present study was similar to The Human Protein Atlas.

In conclusion, SHARPIN expression was reduced in BCC tissues. SHARPIN knockdown increased the expression levels of p-c-JUN and GLI2 in BCC cells. The binding of p-c-JUN and GLI2 may have induced the expression of cyclin D1 and CDK4, promoting cell proliferation and BCC development. However, the present study did not investigate the expression of molecules in the Sonic HH signal pathway, which is as a limitation and requires further research.

\section{Acknowledgements}

The authors would like to thank Dr Jiaman Wang from the Department of Dermatology, Cosmetology and Venereology, Shenzhen Hospital, Southern Medical University for help in reviewing the $\mathrm{BCC}$ pathology and immunohistochemical data. The authors would also like to thank Professor Fu Xiong from the Department of Medical Genetics, Southern Medical University, for providing the research facilities.

\section{Funding}

The present study was supported by the National Natural Science Foundation of China (grant no. 81371724) and Shenzhen Science and Technology Innovation Commission (grant no. JCYJ20160429161334124).

\section{Availability of data and materials}

The datasets used and/or analyzed during the current study are available from the corresponding author on reasonable request.

\section{Authors' contributions}

YHL designed the experiments, guided the study and revised the draft. YY performed the experiments, analyzed the data and prepared the draft. YZ analyzed the data and revised the article. LJT and STZ performed parts of experiments. JNZ collected the tissue samples and performed part of the immunohistochemistry. All authors read and approved the final manuscript.

\section{Ethics approval and consent to participate}

This study was approved by The Ethics Committee of Shenzhen Hospital, Southern Medical University. Written informed consent was obtained from patients and individuals involved in the present study.

\section{Patient consent for publication}

Not applicable.

\section{Competing interests}

The authors declare that they have no competing interests.

\section{References}

1. Roewert-Huber J, Lange-Asschenfeldt B, Stockfleth E and Kerl H: Epidemiology and aetiology of basal cell carcinoma. Br J Dermatol 157 (Suppl 2): S47-S51, 2007.

2. Correia de Sá TR, Silva R and Lopes JM: Basal cell carcinoma of the skin (part 1): Epidemiology, pathology and genetic syndromes. Future Oncol 11: 3011-3021, 2015.

3. Wong CS, Strange RC and Lear JT: Basal cell carcinoma. BMJ 327: 794-798, 2003.

4. Lomas A, Leonardi-Bee J and Bath-Hextall F: A systematic review of worldwide incidence of nonmelanoma skin cancer. Br J Dermatol 166: 1069-1080, 2012.

5. Rubin AI, Chen EH and Ratner D: Basal-cell carcinoma. N Engl J Med 353: 2262-2269, 2005.

6. Martincorena I, Fowler JC, Wabik A, Lawson ARJ, Abascal F, Hall MWJ, Cagan A, Murai K, Mahbubani K, Stratton MR, et al: Somatic mutant clones colonize the human esophagus with age. Science 362: 911-917, 2018.

7. Martincorena I, Roshan A, Gerstung M, Ellis P, Van Loo P, McLaren S, Wedge DC, Fullam A, Alexandrov LB, Tubio JM, et al: Tumor evolution. High burden and pervasive positive selection of somatic mutations in normal human skin. Science 348: 880-886, 2015.

8. Xie J, Aszterbaum M, Zhang X, Bonifas JM, Zachary C, Epstein E and McCormick F: A role of PDGFRalpha in basal cell carcinoma proliferation. Proc Natl Acad Sci USA 98: 9255-9259, 2001.

9. Svärd J, Heby-Henricson K, Persson-Lek M, Rozell B, Lauth M, Bergström A, Ericson J, Toftgård R and Teglund S: Genetic elimination of Suppressor of fused reveals an essential repressor function in the mammalian hedgehog signaling pathway. Dev Cell 10: 187-197, 2006.

10. Vogt A, Chuang PT, Hebert J, Hwang J, Lu Y, Kopelovich L, Athar M, Bickers DR and Epstein EJ Jr: Immunoprevention of basal cell carcinomas with recombinant hedgehog-interacting protein. J Exp Med 199: 753-761, 2004.

11. Athar M, Tang X, Lee JL, Kopelovich L and Kim AL: Hedgehog signalling in skin development and cancer. Exp Dermatol 15: 667-677, 2006.

12. Epstein EH: Basal cell carcinomas: Attack of the hedgehog. Nat Rev Cancer 8: 743-754, 2008.

13. Athar M, Li C, Tang X, Chi S, Zhang X, Kim AL, Tyring SK, Kopelovich L, Hebert J, Epstein EJ Jr, et al: Inhibition of smoothened signaling prevents ultraviolet B-induced basal cell carcinomas through regulation of Fas expression and apoptosis. Cancer Res 64: 7545-7552, 2004.

14. Xie J, Murone M, Luoh SM, Ryan A, Gu Q, Zhang C, Bonifas JM, Lam CW, Hynes M, Goddard A, et al: Activating smoothened mutations in sporadic basal-cell carcinoma. Nature 391: 90-92, 1998. 
15. Lum L and Beachy PA: The hedgehog response network: Sensors, switches, and routers. Science 304: 1755-1759, 2004.

16. Kim MY, Park HJ, Baek SC, Byun DG and Houh D: Mutations of the p53 and PTCH gene in basal cell carcinomas: UV mutation signature and strand bias. J Dermatol Sci 29: 1-9, 2002.

17. Gailani MR, Ståhle-Bäckdahl M, Leffell DJ, Glynn M, Zaphiropoulos PG, Pressman C, Undén AB, Dean M, Brash DE, Bale $\mathrm{AE}$ and Toftgård $\mathrm{R}$ : The role of the human homologue of Drosophila patched in sporadic basal cell carcinomas. Nat Genet 14: 78-81, 1996.

18. Kim J, Aftab BT, Tang JY, Kim D, Lee AH, Rezaee M, Kim J, Chen B, King EM, Borodovsky A, et al: Itraconazole and arsenic trioxide inhibit Hedgehog pathway activation and tumor growth associated with acquired resistance to smoothened antagonists. Cancer Cell 23: 23-34, 2013.

19. Bii VM, Rae DT and Trobridge GD: A novel gammaretroviral shuttle vector insertional mutagenesis screen identifies SHARPIN as a breast cancer metastasis gene and prognostic biomarker. Oncotarget 6: 39507-39520, 2015.

20. Stieglitz B, Haire LF, Dikic I and Rittinger K: Structural analysis of SHARPIN, a subunit of a large multi-protein E3 ubiquitin ligase, reveals a novel dimerization function for the pleckstrin homology superfold. J Biol Chem 287: 20823-20829, 2012.

21. Ikeda F, Deribe YL, Skånland SS, Stieglitz B, Grabbe C, Franz-Wachtel M, van Wijk SJ, Goswami P, Nagy V, Terzic J, et al: SHARPIN forms a linear ubiquitin ligase complex regulating NF- $\kappa B$ activity and apoptosis. Nature 471: 637-641, 2011.

22. Liu J, Wang Y, Gong Y, Fu T, Hu S, Zhou Z and Pan L: Structural insights into SHARPIN-mediated Activation of HOIP for the linear ubiquitin Chain assembly. Cell Rep 21: 27-36, 2017.

23. Fujita H, Tokunaga A, Shimizu S, Whiting AL, Aguilar-Alonso F Takagi K, Walinda E, Sasaki Y, Shimokawa T, Mizushima T, et al: Cooperative domain formation by homologous motifs in HOIL-1L and SHARPIN plays a crucial role in LUBAC stabilization. Cell Rep 23: 1192-1204, 2018.

24. Shimizu S, Fujita H, Sasaki Y, Tsuruyama T, Fukuda K and Iwai K: Differential involvement of the Npl4 zinc finger domains of SHARPIN and HOIL-1L in linear ubiquitin Chain assembly complex-mediated cell death protection. Mol Cell Biol 36: $1569-1583,2016$

25. Liang Y, Seymour RE and Sundberg JP: Inhibition of NF- $\kappa B$ signaling retards eosinophilic dermatitis in SHARPIN-deficient mice. J Invest Dermatol 131: 141-149, 2011.

26. Jung J, Kim JM, Park B, Cheon Y, Lee B, Choo SH, Koh SS and Lee S: Newly identified tumor-associated role of human Sharpin. Mol Cell Biochem 340: 161-167, 2010.

27. Yang H, Yu S, Wang W, Li X, Hou Y, Liu Z, Shi Y, Mu K, Niu G, $\mathrm{Xu}$ J, et al: SHARPIN facilitates $\mathrm{p} 53$ degradation in breast cancer cells. Neoplasia 19: 84-92, 2017.

28. Li J, Lai Y, Cao Y, Du T, Zeng L, Wang G, Chen X, Chen J, Yu Y, Zhang S, et al: SHARPIN overexpression induces tumorigenesis in human prostate cancer LNCaP, DU145 and PC-3 cells via NF- $\mathrm{B} / \mathrm{ERK} / \mathrm{Akt}$ signaling pathway. Med Oncol 32: 444, 2015.

29. Queisser MA, Dada LA, Deiss-Yehiely N, Angulo M, Zhou G Kouri FM, Knab LM, Liu J, Stegh AH, DeCamp MM, et al: HOIL-1L functions as the PKC $\zeta$ ubiquitin ligase to promote lung tumor growth. Am J Respir Crit Care Med 190: 688-698, 2014.

30. Chen B, Zheng Y, Zhu J and Liang Y: SHARPIN overexpression promotes TAK1 expression and activates JNKs and NF- $\mathrm{KB}$ pathway in Mycosis Fungoides. Exp Dermatol 28: 1279-1288, 2019

31. Zhou S, Liang Y, Zhang X, Liao L, Yang Y, Ouyang W and Xu H: SHARPIN promotes melanoma progression via Rapl signaling pathway. J Invest Dermatol: Aug 8, 2019 (Epub ahead of print).

32. Kasperczyk H, Baumann B, Debatin KM and Fulda S: Characterization of sonic hedgehog as a novel NF-kappaB target gene that promotes NF-kappaB-mediated apoptosis resistance and tumor growth in vivo. Faseb J 23: 21-33, 2009.

33. Schumacher MA, Feng R, Aihara E, Engevik AC, Montrose MH, Ottemann KM and Zavros Y: Helicobacter pylori-induced Sonic Hedgehog expression is regulated by NFKB pathway activation: The use of a novel in vitro model to study epithelial response to infection. Helicobacter 20: 19-28, 2015.

34. Yamasaki A, Kameda C, Xu R, Tanaka H, Tasaka T, Chikazawa N, Suzuki H, Morisaki T, Kubo M, Onishi H, et al: Nuclear factor kappaB-activated monocytes contribute to pancreatic cancer progression through the production of Shh. Cancer Immunol Immunother 59: 675-686, 2010.

35. Vile GF, Tanew-Ilitschew A and Tyrrell RM: Activation of NF-kappa B in human skin fibroblasts by the oxidative stress generated by UVA radiation. Photochem Photobiol 62: 463-468, 1995.
36. Tang SC, Liao PY, Hung SJ, Ge JS, Chen SM, Lai JC, Hsiao YP and Yang JH: Topical application of glycolic acid suppresses the UVB induced IL-6, IL-8, MCP-1 and COX-2 inflammation by modulating NF- $\mathrm{KB}$ signaling pathway in keratinocytes and mice skin. J Dermatol Sci 86: 238-248, 2017.

37. Simon MM, Aragane Y, Schwarz A, Luger TA and Schwarz T: UVB light induces nuclear factor kappa B (NF kappa B) activity independently from chromosomal DNA damage in cell-free cytosolic extracts. J Invest Dermatol 102: 422-427, 1994.

38. Budwit-Novotny DA, McCarty KS, Cox EB, Soper JT, Mutch DG, Creasman WT, Flowers JL and McCarty KJ: Immunohistochemical analyses of estrogen receptor in endometrial adenocarcinoma using a monoclonal antibody. Cancer Res 46: 5419-5425, 1986

39. Bollag G, Hirth P, Tsai J, Zhang J, Ibrahim PN, Cho H, Spevak W, Zhang C, Zhang Y, Habets G, et al: Clinical efficacy of a RAF inhibitor needs broad target blockade in BRAF-mutant melanoma. Nature 467: 596-599, 2010.

40. Bai J, Kito Y, Okubo H, Nagayama T and Takeuchi T: Expression of ZNF396 in basal cell carcinoma. Arch Dermatol Res 306: 399-404, 2014

41. Di Gennaro P, Sestini R, Bacci S, Pacini A, Pinzani P, Domenici L, Toscano A, Massi D, Carli P, Genuardi M and Romagnoli P: Tacrolimus causes reduced GLI1 expression and phenotypic changes in the TE 354.T basal cell carcinoma cell line. J Dermatol Sci 54: 52-54, 2009.

42. Colombo I, Sangiovanni E, Maggio R, Mattozzi C, Zava S, Corbett Y,Fumagalli M, Carlino C, Corsetto PA,Scaccabarozzi D, et al: $\mathrm{HaCaT}$ cells as a reliable in vitro differentiation model to dissect the inflammatory/repair response of human keratinocytes. Mediators Inflamm 2017: 7435621, 2017.

43. Yang XY, Wu B, Ma S, Yin L, Wu MC and Li AJ: Decreased expression of ZWINT is associated with poor prognosis in patients with HCC after surgery. Technol Cancer Res Treat 17: 1533033818794190,2018

44. Livak KJ and Schmittgen TD: Analysis of relative gene expression data using real-time quantitative PCR and the 2(-Delta Delta C(T)) method. Methods 25: 402-408, 2001

45. Zhang Y, Huang H, Zhou H, Du T, Zeng L, Cao Y, Chen J, Lai Y, Li J, Wang $\mathrm{G}$ and Guo Z: Activation of nuclear factor $\kappa \mathrm{B}$ pathway and downstream targets survivin and livin by SHARPIN contributes to the progression and metastasis of prostate cancer. Cancer 120: 3208-3218, 2014.

46. De Melo J and Tang D: Elevation of SIPL1 (SHARPIN) increases breast cancer risk. PLoS One 10: e127546, 2015.

47. Miller SJ: Biology of basal cell carcinoma (Part I). J Am Acad Dermatol 24: 1-13, 1991

48. Hanahan D and Weinberg RA: Hallmarks of cancer: The next generation. Cell 144: 646-674, 2011.

49. Susnow N, Zeng L and Margineantu D: Bcl-2 family proteins as regulators of oxidative stress. Semin Cancer Biol 19: 42-49, 2009.

50. Hanahan D and Weinberg RA: The hallmarks of cancer. Cell 100: 57-70, 2000.

51. Ho A and Dowdy SF: Regulation of G(1) cell-cycle progression by oncogenes and tumor suppressor genes. Curr Opin Genet Dev 12: 47-52, 2002

52. Purba TS, Brunken L, Hawkshaw NJ, Peake M, Hardman J and Paus R: A primer for studying cell cycle dynamics of the human hair follicle. Exp Dermatol 25: 663-668, 2016.

53. Dante RA, Larkins BA and Sabelli PA: Cell cycle control and seed development. Front Plant Sci 5: 493, 2014

54. Fernández-Hernández R, Rafel M, Fusté NP, Aguayo RS, Casanova JM, Egea J, Ferrezuelo F and Gari E: Cyclin D1 localizes in the cytoplasm of keratinocytes during skin differentiation and regulates cell-matrix adhesion. Cell Cycle 12: 2510-2517,2013.

55. Xu W and McArthur G: Cell cycle regulation and melanoma. Curr Oncol Rep 18: 34, 2016.

56. Duronio RJ and Xiong Y: Signaling pathways that control cell proliferation. Cold Spring Harb Perspect Biol 5: a008904, 2013.

57. Otsuka A, Levesque MP, Dummer R and Kabashima K Hedgehog signaling in basal cell carcinoma. J Dermatol Sci 78: 95-100, 2015.

58. Daya-Grosjean L and Couvé-Privat S: Sonic hedgehog signaling in basal cell carcinomas. Cancer Lett 225: 181-192, 2005.

59. Mimeault M, Johansson SL, Vankatraman G, Moore E, Henichart JP, Depreux P, Lin MF and Batra SK: Combined targeting of epidermal growth factor receptor and hedgehog signaling by gefitinib and cyclopamine cooperatively improves the cytotoxic effects of docetaxel on metastatic prostate cancer cells. Mol Cancer Ther 6: 967-978, 2007. 
60. Neill GW, Harrison WJ, Ikram MS, Williams TDL, Bianchi LS, Nadendla SK, Green JL, Ghali L, Frischauf AM, O'Toole EA, et al: GLI1 repression of ERK activity correlates with colony formation and impaired migration in human epidermal keratinocytes. Carcinogenesis 29: 738-746, 2008.

61. Riobó NA, Lu K, Ai X, Haines GM and Emerson CP Jr: Phosphoinositide 3-kinase and Akt are essential for sonic hedgehog signaling. Proc Natl Acad Sci USA 103: 4505-4510, 2006.

62. Schnidar H, Eberl M, Klingler S, Mangelberger D, Kasper M, Hauser-Kronberger C, Regl G, Kroismayr R, Moriggl R, Sibilia $\mathrm{M}$ and Aberger F: Epidermal growth factor receptor signaling synergizes with Hedgehog/GLI in oncogenic transformation via activation of the MEK/ERK/JUN pathway. Cancer Res 69: 1284-1292, 2009.

63. Laner-Plamberger S, Kaser A, Paulischta M, HauserKronberger C, Eichberger T and Frischauf AM: Cooperation between GLI and JUN enhances transcription of JUN and selected GLI target genes. Oncogene 28: 1639-1651, 2009.

64. Albanese C, Johnson J, Watanabe G, Eklund N, Vu D, Arnold A and Pestell RG: Transforming p21ras mutants and c-Ets-2 activate the cyclin D1 promoter through distinguishable regions. J Biol Chem 270: 23589-23597, 1995.

65. Johnson GL and Nakamura K: The c-jun kinase/stress-activated pathway: Regulation, function and role in human disease. Biochim Biophys Acta 1773: 1341-1348, 2007.

66. Morrison DK: MAP kinase pathways. Cold Spring Harb Perspect Biol 4, 2012.

67. Zhao HF, Wang J, Jiang HR, Chen ZP and To SS: PI3K p110 $\beta$ isoform synergizes with JNK in the regulation of glioblastoma cell proliferation and migration through Akt and FAK inhibition. J Exp Clin Cancer Res 35: 78, 2016.

68. Johnson RS, Van Lingen B, Papaioannou VE and Spiegelman BM: A null mutation at the c-jun locus causes embryonic lethality and retarded cell growth in culture. Genes Dev 7: 1309-1317, 1993.

69. Zenz R, Scheuch H, Martin P, Frank C, Eferl R, Kenner L, Sibilia $\mathrm{M}$ and Wagner EF: c-Jun regulates eyelid closure and skin tumor development through EGFR signaling. Dev Cell 4 : 879-889, 2003.
70. Zenz R and Wagner EF: Jun signalling in the epidermis: From developmental defects to psoriasis and skin tumors. Int J Biochem Cell Biol 38: 1043-1049, 2006.

71. Regl G, Kasper M, Schnidar H, Eichberger T, Neill GW, Ikram MS, Quinn AG, Philpott MP, Frischauf AM and Aberger F: The zinc-finger transcription factor GLI2 antagonizes contact inhibition and differentiation of human epidermal cells. Oncogene 23: 1263-1274, 2004

72. Gerlach B, Cordier SM, Schmukle AC, Emmerich CH, Rieser E, Haas TL, Webb AI, Rickard JA, Anderton H, Wong WW, et al: Linear ubiquitination prevents inflammation and regulates immune signalling. Nature 471: 591-596, 2011.

73. Tokunaga F, Nakagawa T, Nakahara M, Saeki Y, Taniguchi M, Sakata S, Tanaka K, Nakano H and Iwai K: SHARPIN is a component of the NF- $\kappa \mathrm{B}$-activating linear ubiquitin chain assembly complex. Nature 471: 633-636, 2011.

74. Sivrikoz NO and Kandiloğlu G: The effects of cyclin D1 and Bcl-2 expression on aggressive behavior in basal cell and basosquamous carcinoma. Iran J Pathol 10: 185-191, 2015.

75. Liang SB, Furihata M, Takeuchi T, Iwata J, Chen BK, Sonobe H and Ohtsuki Y: Overexpression of cyclin D1 in nonmelanocytic skin cancer. Virchows Arch 436: 370-376, 2000.

76. Huang K, Huang C, Shan K, Chen J and Li H: Significance of PC cell-derived growth factor and cyclin D1 expression in cutaneous squamous cell carcinoma. Clin Exp Dermatol 37: 411-417, 2012.

77. Bladen JC, Moosajee M, Tracey-White D, Beaconsfield M, O Toole EA and Philpott MP: Analysis of hedgehog signaling in periocular sebaceous carcinoma. Graefes Arch Clin Exp Ophthalmol 256: 853-860, 2018.

(7) $\odot$ This work is licensed under a Creative Commons Attribution-NonCommercial-NoDerivatives 4.0 International (CC BY-NC-ND 4.0) License. 